\title{
Where does Pro-Poor Growth Occur in Vietnam?
}

\author{
NGUYEN HOANG BAO \\ University of Economics HCMC - hoangbao@ueh.edu.vn
}

\begin{abstract}
ARTICLE INFO ABSTRACT
\end{abstract}
Article history:

Received:

Dec. 122013

Received in revised form:

Jan. 242014

Accepted:

Dec. 302014

Keywords:

pro-poor growth, elasticity of poverty with respect to growth, elasticity of poverty with respect to Gini coefficient, simultaneous equation system model.
Although Vietnam's economic growth and poverty reduction for almost three decades have been remarkable, growth for poverty reduction is unequally distributed across the nation. The paper examines the cause of poverty and the impact of provincial economic growth on poverty alleviation, using the data of 63 provinces in Vietnam. The elasticity of poverty with respect to provincial economic growth is employed (the elasticities of headcount index, poverty gap index, and squared poverty index with respect to provincial economic growth) to identify the provinces where pro-poor growth has occurred. The elasticity of poverty with respect to provincial Gini coefficient is examined to identify the impact of expenditure inequality on poverty. The simultaneous equation system is estimated to analyze not only direct and indirect effects of the related variables, but also the causality effect between economic growth and the poverty elasticity with respect to both growth and the Gini coefficient. 


\section{Introduction}

Vietnam's achievements in economic growth and poverty reduction in the past three decades have been remarkable. However, pro-poor growth might be unequally distributed across the nation, and the inequality might impact on poverty. How important are the provincial economic growth rates to poverty alleviation? Does the provincial inequality, which is measured by the Gini coefficient, impact on poverty alleviation? Are there interactions among variables, such as economic growth, poverty alleviation, inequality, and provincial characteristics? These are three fundamental questions to be addressed in this research. To what extent should interests be developed from the above issues? These are important: where economic growth translates into poverty reduction and where it does not, and how provincial inequality impacts on the poor. It would be desirable to quantify the effects of economic growth on poverty alleviation, the effects of inequality on poverty, and the interactions among those variables as an aid to the policy-making process.

The research aims at exploring: (i) effects of provincial economic growth rate on poverty alleviation; (ii) impacts of inequality on poverty reduction; and (iii) interactions of the factors that might directly and indirectly impact on poverty reduction through a simultaneous equation system model. The comparative and descriptive data analysis and the up-to-date techniques of regression analysis are properly used in combination, which makes the magnitude of the coefficients significant. Not only will these methods enable an interesting comparison, but some of the parameters estimated for those provinces may capture the reality during the relevant period.

The needed data are available mainly from the Vietnam Household Living Standards Surveys, the Government Statistical Office, and the World Bank. The studied unit is the province, and the studied period is from 2008 to 2010.

The paper is clearly structured starting with this section as the introduction which consists of the problem statement, significance of study, verification of the data sets employed, and the structure of the paper. Section Two presents theories of the impact of economic growth, inequality and poverty alleviation. Along its summary of a number of important techniques for analyzing the relationships between growth, poverty reduction, and inequality, which have been employed to analyze the case of 63 provinces in Vietnam. While Section Three presents descriptive and comparative data analysis of the economic growth, inequality, and poverty alleviation, the model specification is 
proposed in Section Four. Section Five summarizes the methodological approach, major findings, policy implications of the research, limitations of the study, and suggestions for further research.

\section{Economic growth, inequality, and poverty alleviation: A theoretical survey}

This section, discussing the impacts of the economic growth and inequality on poverty reduction, consists of three subsections: (i) elasticity of poverty with respect to growth and Gini coefficient; (ii) the growth incidence curve; and (iii) rate of pro-poor growth.

\subsection{Elasticity of poverty with respect to growth and Gini coefficient}

The impact of economic growth on poverty reduction has attracted attention of both researchers and policy-makers in recent years. The question is whether or not the economic growth translates into poverty reduction. McKay (2007) introduced the growth elasticity of poverty as a tool for measuring the translation of growth into poverty reduction. If a measure of poverty is denoted as $\mathrm{P}$ (headcount index) and average income as $\mu$, then the elasticity of poverty with respect to growth is simply defined as below:

$$
\varepsilon_{P, \mu}=\frac{\partial P}{\partial \mu} \frac{\mu}{P}
$$

where $\varepsilon_{\mathrm{P}, \mu}$ is the elasticity of poverty with respect to growth; $\mu$ is the average income of the base year; $\mathrm{P}$ is the poverty of the base year; $\partial \mathrm{P}$ is difference in poverty between the current year and base year; and $\partial \mu$ is difference in income between the current year and base year.

Elasticity of poverty with respect to growth $\left(\varepsilon_{\mathrm{P}, \mu}\right)$ measures the percentage change in a poverty measure in response to a one-percent increase in average income. If the growth reduces poverty, this elasticity will have a negative sign. The magnitude of this elasticity measures the sensitiveness of poverty alleviation with respect to growth. If this elasticity is near to zero, the economic growth is indifferent to poverty reduction. One would expect that an increase in growth will reduce the headcount index. This is a total elasticity of growth. It does not assume that the distribution has been held constant. It is also possible to compute elasticities of poverty with respect to growth assuming the unchanged distribution (Datt \& Ravallion, 1992). To exclude the impact of inequality 
on the growth elasticity of poverty, the elasticity of poverty with respect to Gini coefficient is estimated to identify whether the distribution increases (or decreases) the poverty:

$$
\varepsilon_{P, G i n i}=\frac{\partial P}{\partial G i n i} \frac{G i n i}{P}
$$

where $\varepsilon_{P, G}$ is the elasticity of poverty with respect to Gini coefficient; Gini is the Gini coefficient of the base year; $\mathrm{P}$ is the poverty of the base year; $\partial \mathrm{P}$ is difference in poverty between the current year and base year; and, $\partial$ Gini is difference in Gini coefficient between the current year and base year.

Sen, Mujeri and Shahabuddin (2004) estimated the headcount index-actual using the data for Bangladesh and Gini coefficient at three points in time: 1992, 1996 and 2000, and then excluded the change in distribution of income by fixing the Gini coefficient. Because the headcount index (stimulated if inequality unchanged) is lower than the actual index, the study of the effect of growth on poverty reduction can ignore the noise of inequality.

\subsection{Growth incidence curves}

Ravallion and Chen (2003) set the analytic foundations for the growth incidence curve: the horizontal axis represents the different percentile groups of the population (the poorest $1 \%$ of the population, the second percentile and so up to the richest $1 \%$ ), where the vertical axis represents the annual change in the consumption measure between the two points of time for each percentile group. If the growth incidence curve is always on the positive side, the consumption of all levels of percentile has increased between the two points in time. If the slope of the curve is upward, the consumption (or income) increases faster from richer to poorer states. This implies that the inequality increases, as in the case of Bangladesh (Sen, Mujeri \& Shahabuddin, 2004). The growth incidence curve is always above the zero line and upward, indicating that the poverty had fallen but growth tended to increase inequality more than it alleviated poverty. This case is different in Indonesia when this country's economy was affected by the East Asian crisis in 1997 (Timmer, 2005); the curve is below the zero line and downward- 
sloping. Poverty increased, and the crisis seemingly hit the higher percentile group harder than lower percentile groups.

The growth incidence curve can be very valuable to apply the same technique to subgroups of the population, for example, distinguishing urban and rural areas, or different regions. In an example of Ghana, the growth incidence curve of national level suggested positive growth in all percentile groups over the surveyed period. However, computing growth incidence curve for subnational groups revealed that there was negative growth for substantial numbers of households in the Northern Savannah region (McKay, 2007). This information was not revealed in the national growth incidence curve because of the average it implied.

\subsection{Rate of pro-poor growth}

The country studies, in the Operationalizing Pro-Poor Growth Research Program (OPPG) focused more on the absolute concept of pro-poor growth developed by Ravallion and Chen (2003). But for many purposes, analysts may prefer to compute relative concepts, the examples of which are discussed by Kakwani and Pernia (2000), and Kakwani, Khandker and Son (2004).

Ravallion and Chen (2003)'s concept of the rate of pro-poor growth is the average growth rate in percentiles which were poor in the first period. This is related to an absolute concept of pro-poor growth, by answering the question of whether the growth reduces poverty. It is also closely related to the growth incidence curve; the rate of propoor growth is equal to the average growth rate of all percentiles up to the poverty line, which is not the same as the growth rate of mean income of the poor. If the rate of propoor growth is higher than the ordinary growth rate (mean growth rate for the whole population), then growth is pro-poor in a relative sense; if lower, it indicates that growth is associated with increasing inequality between poor and non-poor households.

The rate of pro-poor growth can also be computed for groups of the population. The relationship between the rate of pro-poor growth and the mean growth rate can be illustrated by adding to the growth incidence curve a horizontal line for the overall growth rate. Rates of pro-poor growth can be computed for different poverty lines, and will be specific to the poverty line chosen. This can be of value in looking at rates of growth among the poorest. 


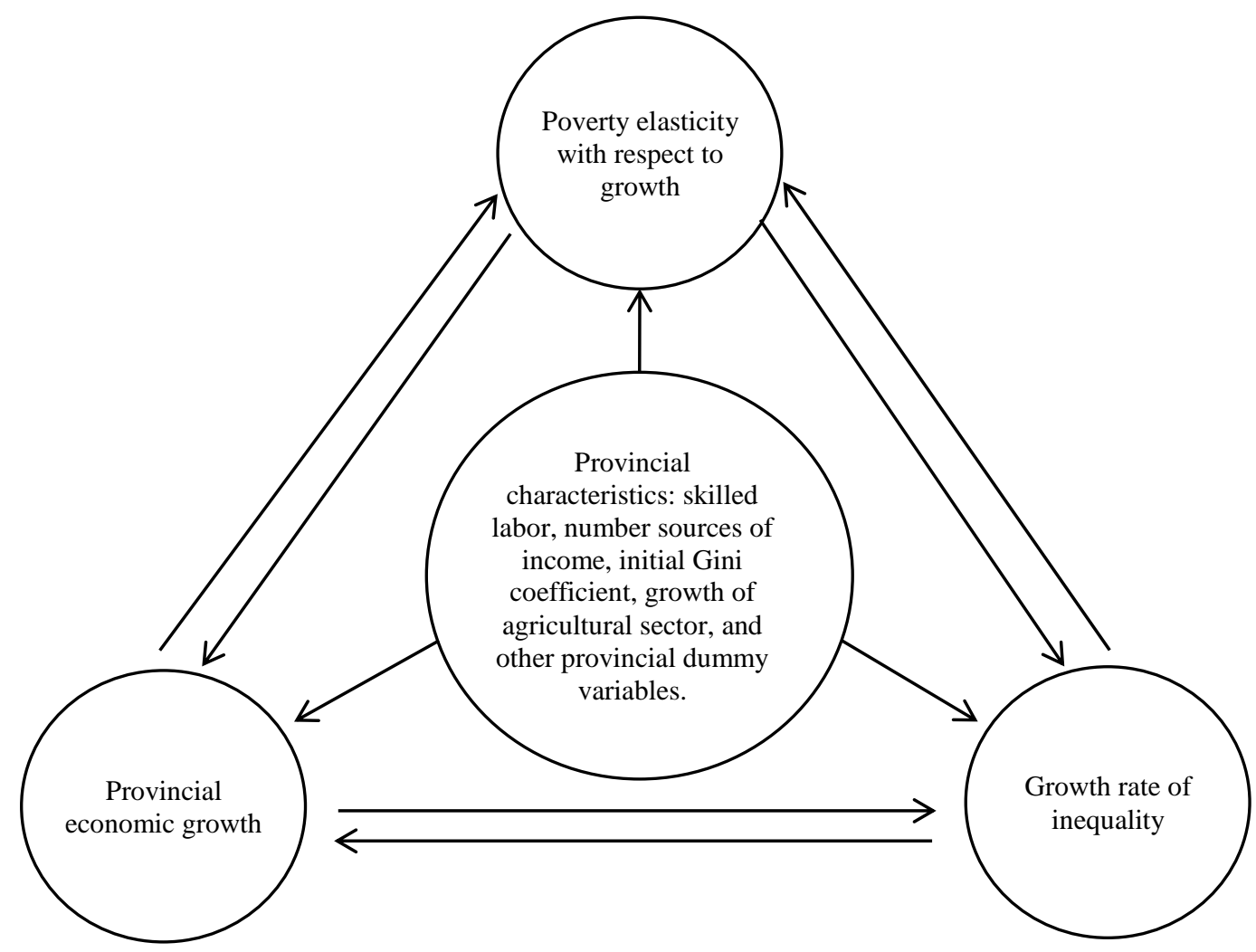

Fig. 1. The framework of study

The simultaneous equation system approach is used to capture the interactions among variables, such as poverty elasticity with respect to growth, poverty elasticity with respect to Gini, economic growth, and some provincial characteristics employed as the control variables.

\section{Economic growth and poverty alleviation in Vietnam: Comparative and descriptive data analysis}

As a preliminary to the simultaneous equations approach in the next section, this section presents a brief review of some summary data on the relationships between provincial poverty and economic growth, and between provincial poverty and inequality. 


\subsection{Poverty elasticity and economic growth}

The priority requirement for the process of industrialization is the pro-poor growth. To measure the poverty, the poverty rate $\left(\mathrm{P}_{0}\right)$, the poverty gap $\left(\mathrm{P}_{1}\right)$, and the squared poverty gap $\left(\mathrm{P}_{2}\right)$ are used along the line suggested by Foster, Green and Thorbeoke (1984). The general formula can be written as follows:

$$
P_{\alpha}=\frac{1}{n} \sum_{i=1}^{q}\left(\frac{z-y i}{z}\right)^{\alpha}
$$

where $\mathrm{n}$ is the total number of households surveyed; $\mathrm{q}$ is the number of households that are poor; $z$ is the poverty line; $y i$ is the household income $i$; and $\alpha$ is a parameter reflecting the weight placed on the depth of poverty. The interpretation of the index depends on the value of $\alpha$. The extent of poverty is commonly summarized as a headcount measure ( $\alpha=0$; the proportion of a given population that are poor), as poverty gap index ( $\alpha=1$; taking account of the average shortfall below the poverty line), and, as the squared poverty gap index ( $\alpha=2$, placing still greater weight on the poorest among the poor, and thus being sensitive to inequality among the poor) [1].

The importance of growth for poverty reduction is widely accepted by researchers and policy-makers. Nevertheless, there is a substantial variation in the extent to which growth translates into poverty reduction. The growth elasticity of poverty gives a measure of how effectively growth is translated into poverty reduction, and can be used as a starting point to identify the factors that might enhance this effectiveness.

Where does the pro-poor growth occur in Vietnam? The data sets of GRDP for 63 provinces in Vietnam are collected from the Government Statistical Office in Vietnam. The elasticities of poverty $\left(\mathrm{P}_{0}, \mathrm{P}_{1}\right.$, and $\left.\mathrm{P}_{2}\right)$ with respect to economic growth are calculated. The elasticity of the headcount index with respect to growth can be written as follows:

$$
E_{g_{i}}^{P_{0 i}}=\frac{\frac{P_{0 i}^{2010}-P_{0 i}^{2008}}{P_{0 i}^{2008}}}{\frac{G D P_{i}^{2010}-G D P_{i}^{2008}}{G D P_{i}^{2008}}} \quad i=\overline{1,63}
$$

where $E_{g_{i}}^{P_{0 i}}$ is the elasticity of headcount index with respect to growth in the province $\mathrm{i}(i=\overline{1,63}) ; P_{0 i}^{2010}$ and $P_{0 i}^{2008}$ are the headcount indexes of the province $\mathrm{i}(i=\overline{1,63})$ in 
the years 2010 and 2008 respectively $(i=\overline{1,63})$; and $G D P_{i}^{2010}$ and $G D P_{i}^{2008}$ are the GDP of province $\mathrm{i}(i=\overline{1,63})$ in the years 2010 and 2008 respectively.

The elasticity shows the percentage decrease/increase in headcount index caused by a one-percent increase in GRDP of province $i$ within two surveyed years. The provincial pro-poor growth might be comparatively identified.

The provinces of Quang Ngai and Bac Ninh are excluded from the data sets because they are the outliers (extremely high economic growth rates). The headcount index of Da Nang is equal to zero and also excluded from the data sets. The average of national economic growth rate and average of national elasticity of headcount index with respect to growth are calculated and drawn in Fig. 2. The impact of economic growth on poverty reduction comparatively varies across the country. Based on the average of national growth and average of national elasticity of headcount index, the four zones are clearly identified as below:

(i) Ha Nam, Binh Duong, Hanoi, Phu Yen, Binh Phuoc, Long An, Dong Thap and many other provinces (the lower-right corner of Fig. 2) attained high economic growth rates and poverty reduction. Those provinces have successfully achieved pro-poor growth and two national goals at the same time - high economic growth and sharp poverty reduction.

(ii) HCMC and Quang Tri Province (the upper-right corner of Fig. 2) attained high economic growth, but the elasticities of headcount index with respect to growth increased. The reason for this is the fact that the impact of world economic recession has severely occurred in the two provinces.

(iii) Ninh Thuan, Bac Lieu, Tra Vinh, Ba Ria-Vung Tau, Thai Nguyen, Cao Bang, Hai Duong, Binh Dinh and many other provinces (the lower-left corner of Fig. 2) did not achieve high economic growth, but they improved the poverty rates substantially.

(iv) Dong Nai, Quang Ninh, Dak Nong, and Binh Thuan provinces suffered not only low economic growth rates, but also higher poverty rates (the upper-left corner of Fig. 2 ). Those provinces did not achieve both of the national goals. 


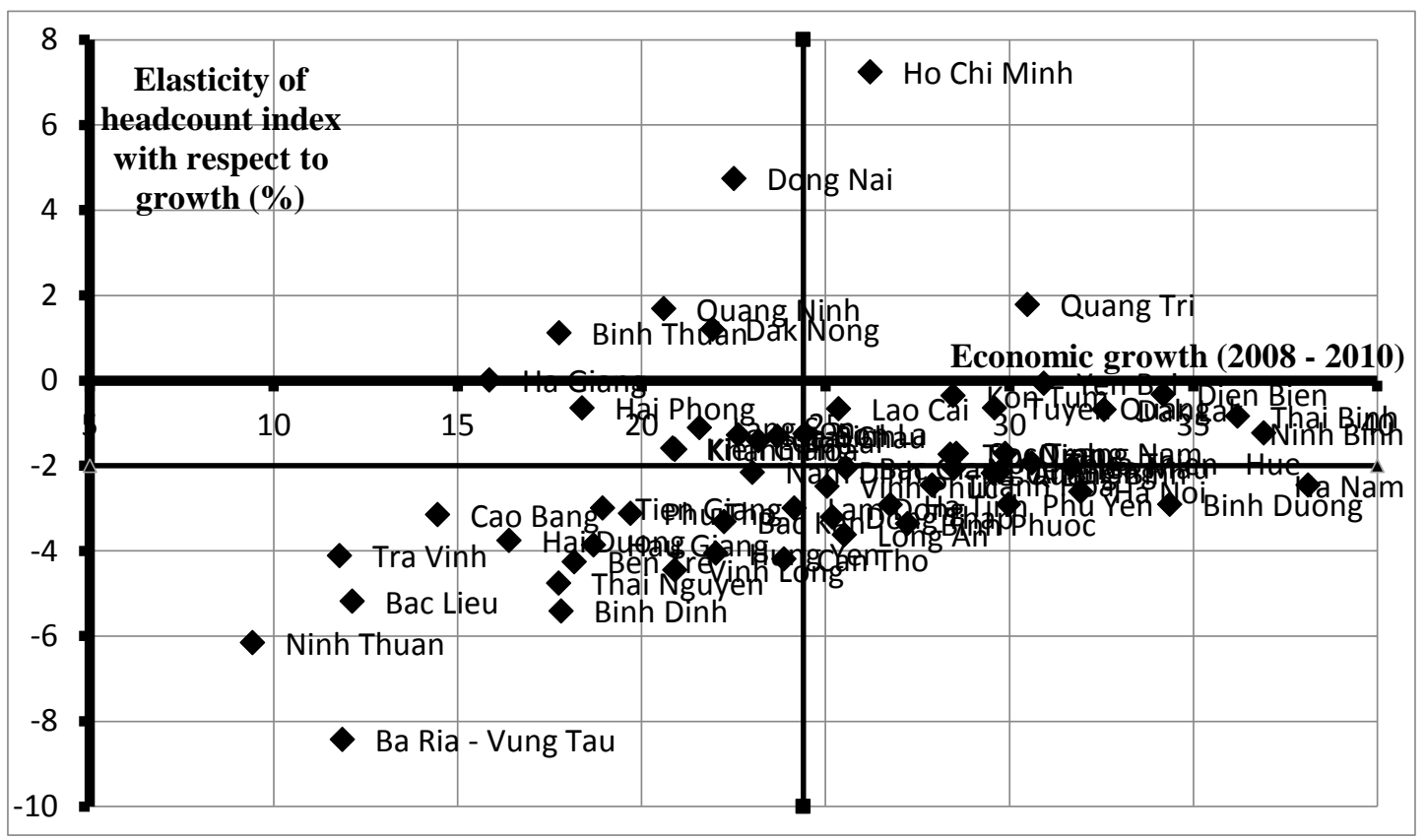

Fig. 2. Provincial elasticity of headcount index with respect to growth versus economic growth $(2008-2010)$

Note: The vertical straight line is the average of national economic growth; the horizontal straight line is the average of national elasticity of headcount index with respect to economic growth.

Source: Calculated from the Vietnamese Living Standard Surveys (VHLSS2010 and VHLSS 2008) and The Government Statistical Office of Vietnam (GSO, 2013).

Poverty gap index is a measure of the intensity of poverty. It is defined as the average poverty gap in the population as a proportion of the poverty line. The poverty gap index is an improvement over the headcount ratio as a measure of poverty which simply counts all the people below a poverty line, in a given population, and considers them equally poor. Poverty gap index estimates the depth of poverty by considering how far, on the average, the poor are from that poverty line. Thus, the elasticity of the poverty gap index with respect to growth measures how much a one-percent increase in the growth rate reduces the depth of the poverty. The average of national economic growth rate and the average of national elasticity of poverty gap index with respect to growth are calculated and drawn in the Fig. 3. 
There are some extreme data points which are excluded from the data sets: (i) Quang Ngai and Bac Ninh provinces have high economic growth rates; (ii) The headcount index of Da Nang is equal to zero; and, (iii) The elasticities of poverty gap index of the HCMC and Dong Nai province are $12 \%$ and $6 \%$ respectively. Both of the provinces are the outliers.

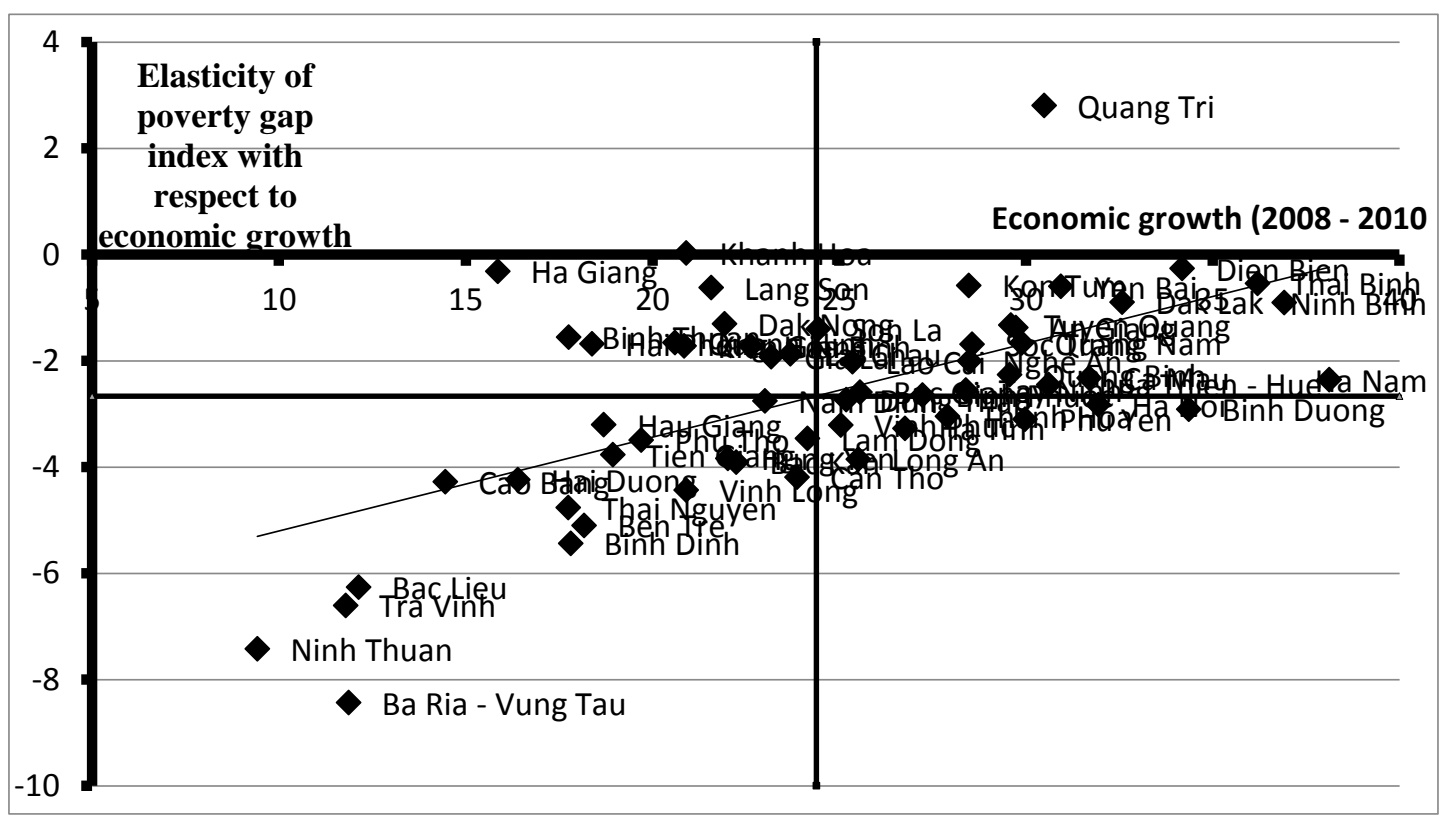

Fig. 3. Provincial elasticity of poverty gap index with respect to growth versus economic growth (2008 - 2010)

Note: The vertical straight line is the average of national economic growth; the horizontal straight line is the average of national elasticity of poverty gap index with respect to economic growth.

Source: Calculated from the Vietnamese Living Standard Surveys (VHLSS2010 and VHLSS 2008) and The Government Statistical Office of Vietnam (GSO, 2013).

One of the interesting findings is a close linear relationship between the economic growth and the elasticity of the poverty gap index, except the extremely positive data points of Quang Tri and extremely negative data points of Ba Ria-Vung Tau, Ninh Thuan, Tra Vinh, and Bac Lieu (Fig. 3). It is apparent that economic growth tends to sharpen the depth of the poverty.

The squared poverty gap index determines the sharpening of income gap within poverty population. This method squares the poverty gap for each household, and thus 
puts more emphasis on the observations that fall far away from the poverty line rather than those who are closer. The squared poverty gap index is very similar to the poverty gap index because it also weighs the poor based on how poor they are. The difference between them is that the shortfalls of people below the poverty line are squared, giving the very poor much more weight than those who fall only a few cents short of the poverty line. The squared poverty gap index is more beneficial to the poor who are further away from the poverty line because they will not receive the same amount of aid from the government. It sharpens the gap within the poor. As for provinces with the same poverty gap index, the province that has a lower squared poverty gap index is more likely to succeed in reducing the poverty than provinces with higher ones.

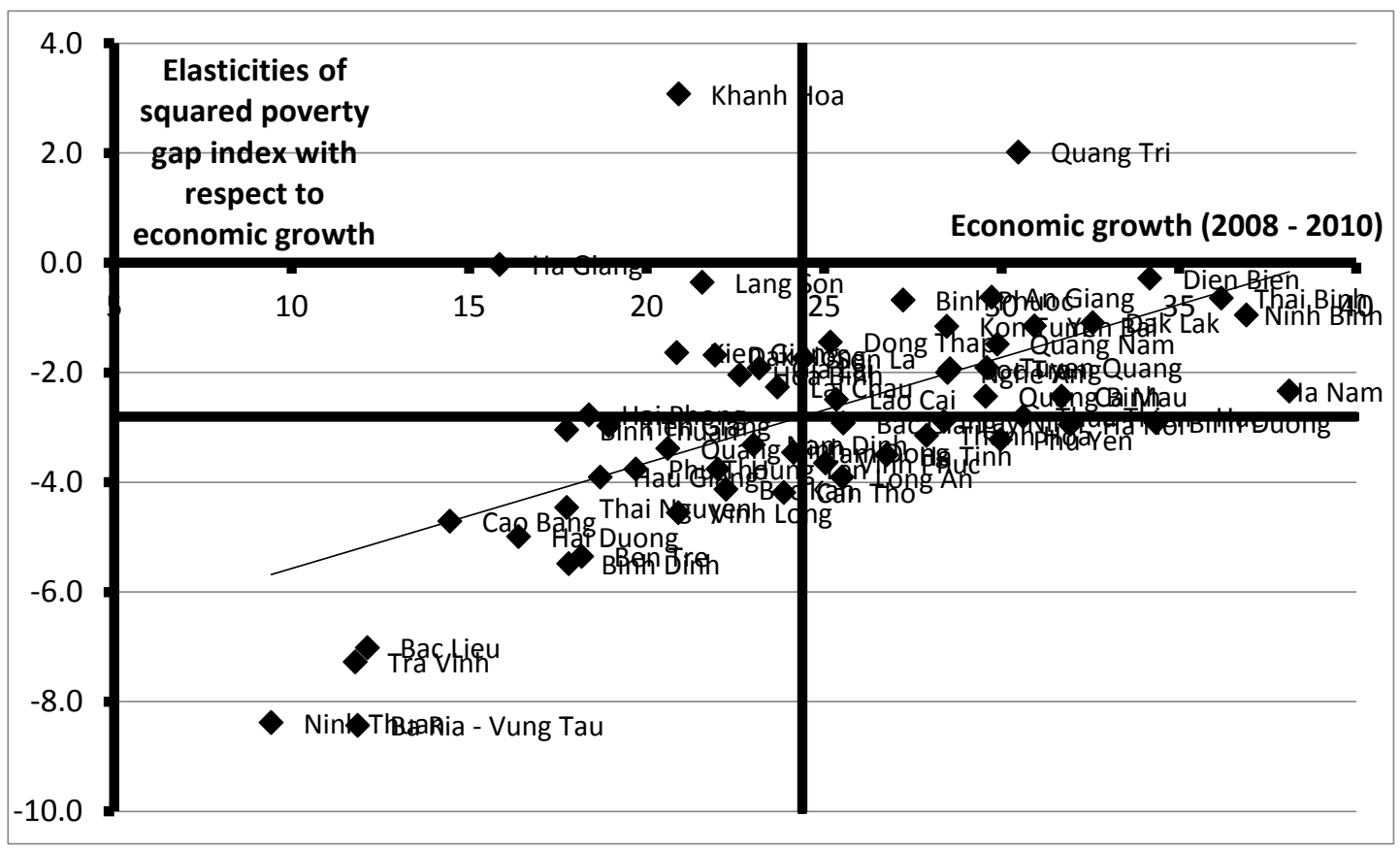

Fig. 4. Provincial elasticity of squared poverty gap index with respect to growth versus economic growth $(2008-2010)$

Note: The vertical straight line is the average of national economic growth; the horizontal straight line is the average of national elasticity of squared poverty gap index with respect to economic growth. Source: Calculated from the Vietnamese Living Standard Surveys (VHLSS2010 and VHLSS 2008) and The Government Statistical Office of Vietnam (GSO, 2013). 
The economic growth has positively impacted on elasticities of squared poverty gap index for growth, except the positive data points of Khanh Hoa, Quang Tri, Lạng Sơn, and Ha Giang and the negative data points of Ba Ria-Vung Tau, Ninh Thuan, Bac Lieu, and Tra Vinh (Fig. 4).

\subsection{Poverty elasticity and inequality}

The expenditure/income inequality might impact on the poverty. Based on the formula (2), the elasticity of the headcount index with respect to Gini can be written as follows:

$$
E_{\text {Gini }_{i}}^{P_{0 i}}=\frac{\frac{P_{0 i}^{2010}-P_{0 i}^{2008}}{P_{0 i}^{2008}}}{\frac{\operatorname{Gini}_{i}^{2010}-G i n i_{i}^{2008}}{G i n i_{i}^{2008}}} \quad i=\overline{1,63}
$$

where $E_{G i n i_{i}}^{P_{0 i}}$ is the elasticity of headcount index with respect to Gini in the province $\mathrm{i}(i=\overline{1,63}) ; P_{0 i}^{2010}$ and $P_{0 i}^{2008}$ are the headcount indexes of the province $\mathrm{i}(i=\overline{1,63})$ in the years 2010 and 2008 respectively $(i=\overline{1,63})$; and $\operatorname{Gini}_{i}^{2010}$ and $\operatorname{Gini}_{i}^{2008}$ are the Gini of province $\mathrm{i}(i=\overline{1,63})$ in the years 2010 and 2008 respectively.

The elasticity shows the percentage decrease/increase in headcount index caused by a one-percent increase in Gini of province i within two years. The impact of income inequality on poverty elasticities might be comparatively observed. 


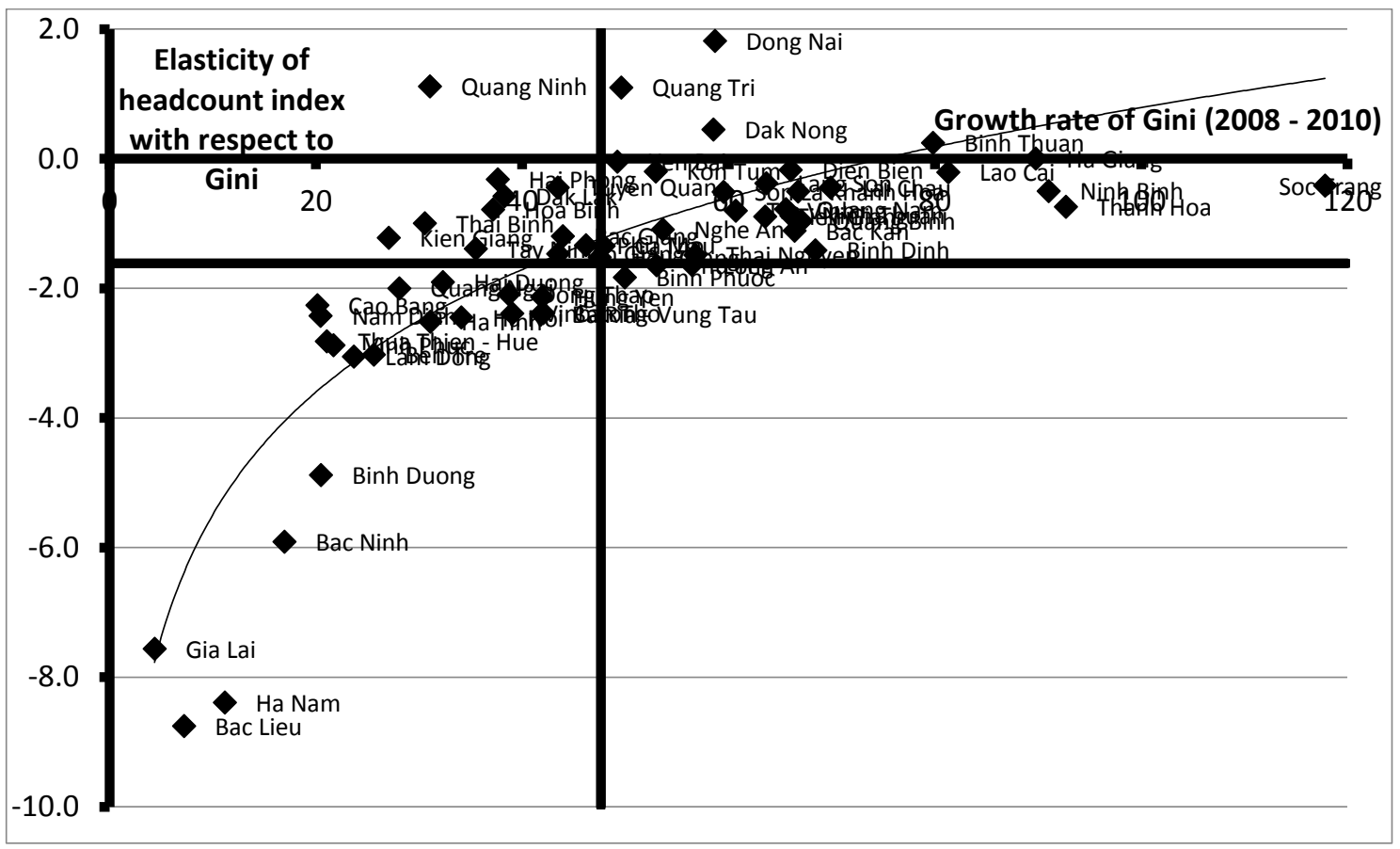

Fig. 5. Elasticity of headcount index with respect to Gini versus Gini coefficient Sources: Calculated from the VHLSS2010 and VHLSS 2008

The headcount index of Da Nang province is equal to zero and therefore excluded from the data sets. HCMC is also excluded from the data sets because its Gini elasticity of headcount index is comparatively high (8.4\%). There is striking evidence that the higher growth rate of Gini leads to the lower elasticity of headcount with respect to Gini. The widening growth rate of the gap between the rich and the poor strongly impacts on the process of poverty reduction. There is a close non-linear relationship between the two variables. Dong Nai, Quang Tri, Dak Nong, and Quang Ninh provinces are the outliers which have strongly positive elasticities of headcount index of Gini. 


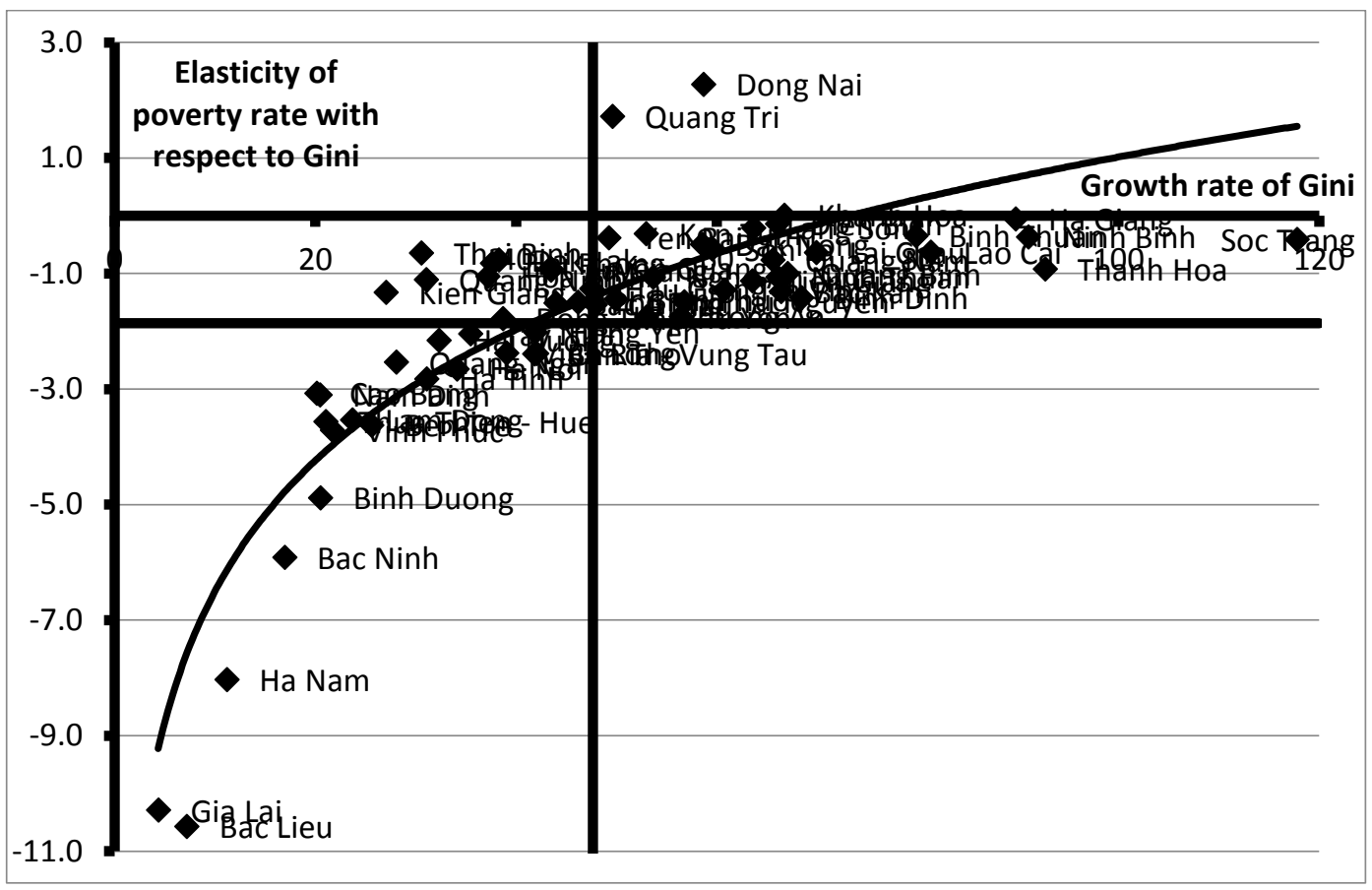

Fig. 6. Elasticity of poverty rate index with respect to Gini versus Gini growth rate Source: Calculated from the VHLSS2010 and VHLSS 2008 


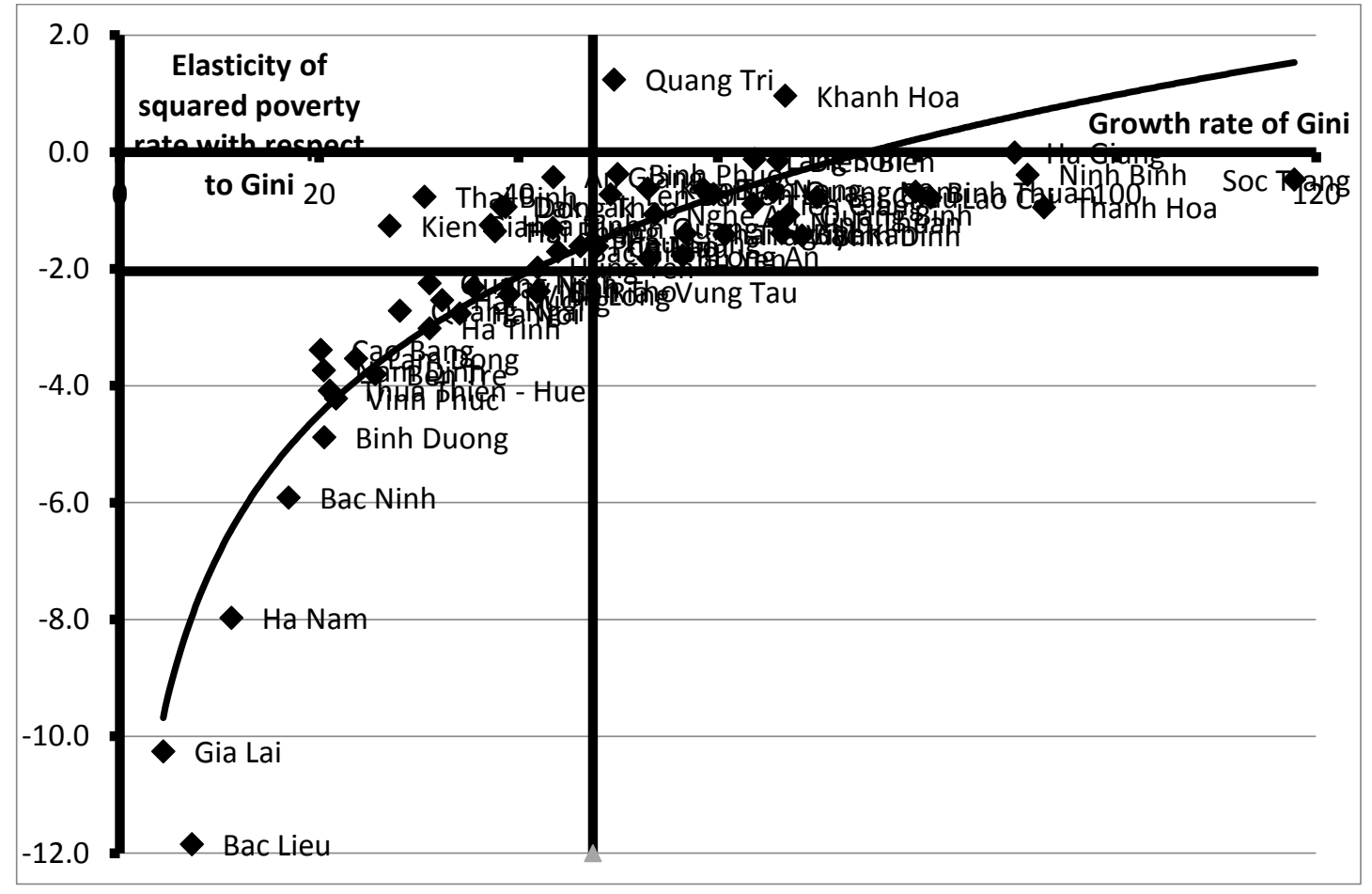

Fig. 7. Elasticity of squared poverty rate with respect to Gini versus Gini coefficient Source: Calculated from the VHLSS2010 and VHLSS 2008

There are statistically significant and non-linear impacts of growth of Gini on elasticity of poverty gap and squared poverty gap indexes. Provinces with high growth of Gini usually find it difficult to reduce the poverty rate and the depth of the poverty. The analysis also picks up some outliers.

\section{Economic growth and poverty alleviation: Simultaneous equations system approach}

In spite of some preliminary findings presented by descriptive and comparative data analysis and single equation approach, they might suffer from the biased estimations to some extent. The results also point out the need for examining the mechanism through which economic growth and inequality affect the poverty. This section is devoted to the specification and estimation of a simultaneous equation system model along its discourse upon: (i) the characteristics of the simultaneous equation model; (ii) the structure of the 
socio-economic behavioral function system model; and (iii) the model results and major findings.

\subsection{Characteristics of the simultaneous equation model}

The simultaneous equation system model has a number of characteristics to be considered: (i) the exogenous variable in a one-equation regression model which might become a dependent variable in the another behavioral function in the simultaneous equation system, (ii) there possibly are complicated interactions and feedback effects among endogenous variables, and (iii) the simultaneous equation system model explains the socioeconomic mechanism through which the policy-makers might observe direct and indirect impacts on the concerned variables. The direction of causality is also taken into account.

\subsection{Structure of socioeconomic behavioral system model}

The growth elasticity of poverty can be written as follows:

$\mathrm{e}_{i} \mathrm{P}_{\mathrm{j}}=\mathrm{f}\left(\mathrm{Gini}_{\mathrm{i}}{ }^{2008}, \mathrm{~g}_{\mathrm{i}}\right.$ Gini, $\mathrm{GDP}_{\mathrm{i}}{ }^{2008}, \mathrm{~g}_{\mathrm{i}}, \mathrm{g}_{\mathrm{i} \_}$skill, Dummy_eP0 $)$

where $e_{i} P_{j}$ (i is the province $i[i=\overline{1,63}]$ and $j=0,1,2$ ) are the growth elasticity of poverty rate $(j=0)$, the growth elasticity of poverty gap $(j=1)$, and growth elasticity of squared poverty gap $(\mathrm{j}=2)$ of the province i respectively;

Gini $_{i}{ }^{2008}$ is the initial level of expenditure inequality in the province $i$ in the base year 2008. If the initial inequality is comparatively higher, the poverty elasticity will tend to be lower along the line suggested by McKay (2007); $\mathrm{g}_{-}$Gini is the growth rate of the Gini coefficient at the province $i$ between the years 2010 and 2008. If $g_{i}$ Gini increases, the poverty rate of growth will increase. It is difficult to attack poverty with a high growth rate of inequality;

$\mathrm{GDP}_{\mathrm{i}}{ }^{2008}$ is the initial level of the gross products of the province $\mathrm{i}$ in the base year 2008; $\mathrm{g}_{\mathrm{i}}$ is the provincial economic growth rate in the period 2008-2010; and $\mathrm{g}_{\mathrm{i}}$ is expected to have positive impacts on the growth elasticity of poverty; $\mathrm{g}_{\mathrm{i}}$ unskill is the growth rate of skilled labor force in the province i between those two years (2008-2010); and Dummy_eP0 is the dummy variable (Dummy_eP0 $=1$ if the growth elasticity of povety rate is greater than zero and Dummy_eP0 $=0$ if the growth elasticity of poverty 
rate is less than zero). The dummy variable is properly used to pick up some extreme data points.

The behavioral function of the provincial economic growth might be explained by:

gi $=\mathrm{f}($ ei_Pj, gi_agri, gi_skill)

where $\mathrm{g}_{\mathrm{i}}$ is the provincial economic growth rate in the period 2008-2010; $\mathrm{e}_{\mathrm{i}} \mathrm{P}_{\mathrm{j}}(\mathrm{i}$ is the province $i[i=\overline{1,63}]$ and $j=0,1,2)$ are the growth elasticity of poverty rate $(j=0)$, the growth elasticity of poverty gap $(j=1)$, and growth elasticity of squared poverty gap $(j=2)$ of the province i respectively; $\mathrm{g}_{\mathrm{i}}$ agri is the growth of agricultural sector in the province $\mathrm{i}(\mathrm{i}=\overline{1,63})$; and $\mathrm{g}_{\mathrm{i} \_}$skill is the growth rate of skilled labor force of the province $\mathrm{i}$ between those two years (2008-2010).

The behavioral function of the growth of expenditure inequality is defined as follows:

$\mathrm{g}_{\mathrm{i}}$ Gini $=\mathrm{f}\left(\mathrm{g}_{\mathrm{i}}\right.$ sources, $\mathrm{g}_{\mathrm{i}}$ skill $)$

where $\mathrm{g}_{\mathrm{i}}$ ssources is the growth of household income sources in the province $\mathrm{i}, \mathrm{i}$ ( $\mathrm{i}=$ $\overline{1,63}$ ) between 2008 and 2010 (the number of channels through which a household can earn money, ignoring the monetary earnings from each channel). The household that has various income sources might widen the growth rate of the gap between the rich and the poor; and higher growth rates of skilled labor force in the province i will make the $\mathrm{g}_{\mathrm{i}}$ Gini increase.

\subsection{Model results and findings}

To explain the interactions of the provincial elasticity of poverty of growth, expenditure inequality, and economic growth, the simultaneous equation system, consisting of equations (6), (7), and (8), is properly used. The data sets of model are calculated, employing results from VHLSS2010 and VHLSS2008. The estimated results are summarized as follows:

Growth elasticity of poverty rate $(\mathrm{j}=0)$

$$
\begin{aligned}
& \text { eP0_g }=-11.981+0.131 \mathrm{Gini}^{2008}+0.016 \mathrm{~g} \_ \text {Gini }+0.181 \mathrm{~g}+0.126 \mathrm{~g} \_ \text {skill }+5.121 \text { Dum_eP0 } \\
& \begin{array}{lllll}
(1.641) & (0.041) \quad(0.009) & (0.026) & (0.054)
\end{array} \\
& \mathrm{g}=16.582+0.556 \text { eP0_g }-0.724 \text { g_agri }-0.258 \text { g_skill } \\
& \begin{array}{llll}
(1.863) & (0.254) \quad(0.103) \quad(0.176)
\end{array} \\
& \text { g_Gini }=55.029+0.712 \mathrm{~g} \_ \text {sources }-1.972 \mathrm{~g} \_ \text {skill } \\
& \text { (3.526) (0.405) (0.808) }
\end{aligned}
$$

Growth elasticity of poverty gap $(j=1)$ 


$$
\begin{aligned}
& \text { eP1_g }=-11.851+0.103 \text { Gini }^{2008}+0.020 \mathrm{~g} \_ \text {Gini }+0.195 \mathrm{~g}+0.142 \mathrm{~g} \_ \text {skill }+6.776 \text { Dum_eP1 } \\
& \begin{array}{lllll}
(2.293) & (0.056) \quad(0.012) \quad(0.036) & (0.080) & (0.1018)
\end{array} \\
& \mathrm{g}=17.669+0.620 \text { eP1_g }-0.681 \mathrm{~g} \_ \text {agri }-0.347 \mathrm{~g} \_ \text {skill } \\
& \begin{array}{lll}
(1.911) & (0.218) \quad(0.103) \quad(0.178)
\end{array} \\
& \text { g_Gini }=55.029+0.712 \mathrm{~g} \_ \text {sources }-1.972 \mathrm{~g} \_ \text {skill } \\
& \text { (3.526) (0.405) (0.808) }
\end{aligned}
$$

Growth elasticity of squared poverty gap $(\mathrm{j}=2)$

$$
\begin{aligned}
& \text { eP2_g }=-20.795+0.244 \mathrm{Gini}^{2008}+0.054 \mathrm{~g} \_ \text {Gini }+0.290 \mathrm{~g}+0.686 \mathrm{~g} \_ \text {skill } \\
& \begin{array}{lllll}
(4.727) & (0.117) \quad(0.024) & (0.075) & (0.151)
\end{array} \\
& \mathrm{g}=16.410+0.339 \mathrm{eP} 2 \_\mathrm{g}-0.724 \mathrm{~g} \_ \text {agri }-0.346 \mathrm{~g} \_ \text {skill } \\
& \text { (1.771) (0.144) (0.101) (0.187) } \\
& \text { g_Gini }=55.029+0.712 \text { g_sources }-1.972 \text { g_skill } \\
& \text { (3.526) (0.405) (0.808) }
\end{aligned}
$$

The standard errors are in the parentheses. All explanatory variables are statistically significantly different from zero. The outcomes of the simultaneous equation model and the policy implications are as follows:

Elasticity of poverty rate with respect to growth

(i) The Gini coefficient in the base year 2008 based on the initial expenditure inequality has statistically affected the poverty rate elasticity with respect to growth (Equation 9). It means that a higher initial level of expenditure inequality will lead to reduction in the growth elasticity of poverty rate (or a higher level of growth elasticity of poverty rate). It is difficult for the provinces with higher level of expenditure inequality to attack the poverty;

(ii) The growth of Gini coefficient has also impacted on the growth elasticity of poverty rate. The efforts to deal with poverty depend on not only the initial level of expenditure inequality, but also the speed of expenditure inequality along the line suggested by McKay (2007);

(iii) As shown in Fig. 3 and the model results from Equation 9, the higher level of provincial economic growth tends to produce a higher growth elasticity of poverty rate (i.e. lower level of poverty reduction). Provinces with high economic growth rates have comparatively low levels of poverty rate. Thus, it is difficult for those provinces to further reduce poverty rate; 
(iv) There are two channels through which the extension of skilled labor force affects the growth elasticity of poverty rate: direct and indirect channels. In the former the extension of skilled labor force has negative impacts on the growth elasticity of poverty rate. In the latter the extension of skilled labor force negatively impacts on the speed of expenditure inequality (Equation 11) and the speed of expenditure inequality positively impacts on growth elasticity of poverty rate. Another indirect effect is that the extension of skilled labor force negatively impacts on economic growth and the economic growth positively affects the poverty rate elasticity with respect to economic growth. The net effects of the extension of skilled labor force positively makes the growth elasticity of poverty rate approach the zero value, i.e. the extension of skilled labor force is indifferent to growth elasticity of poverty rate.

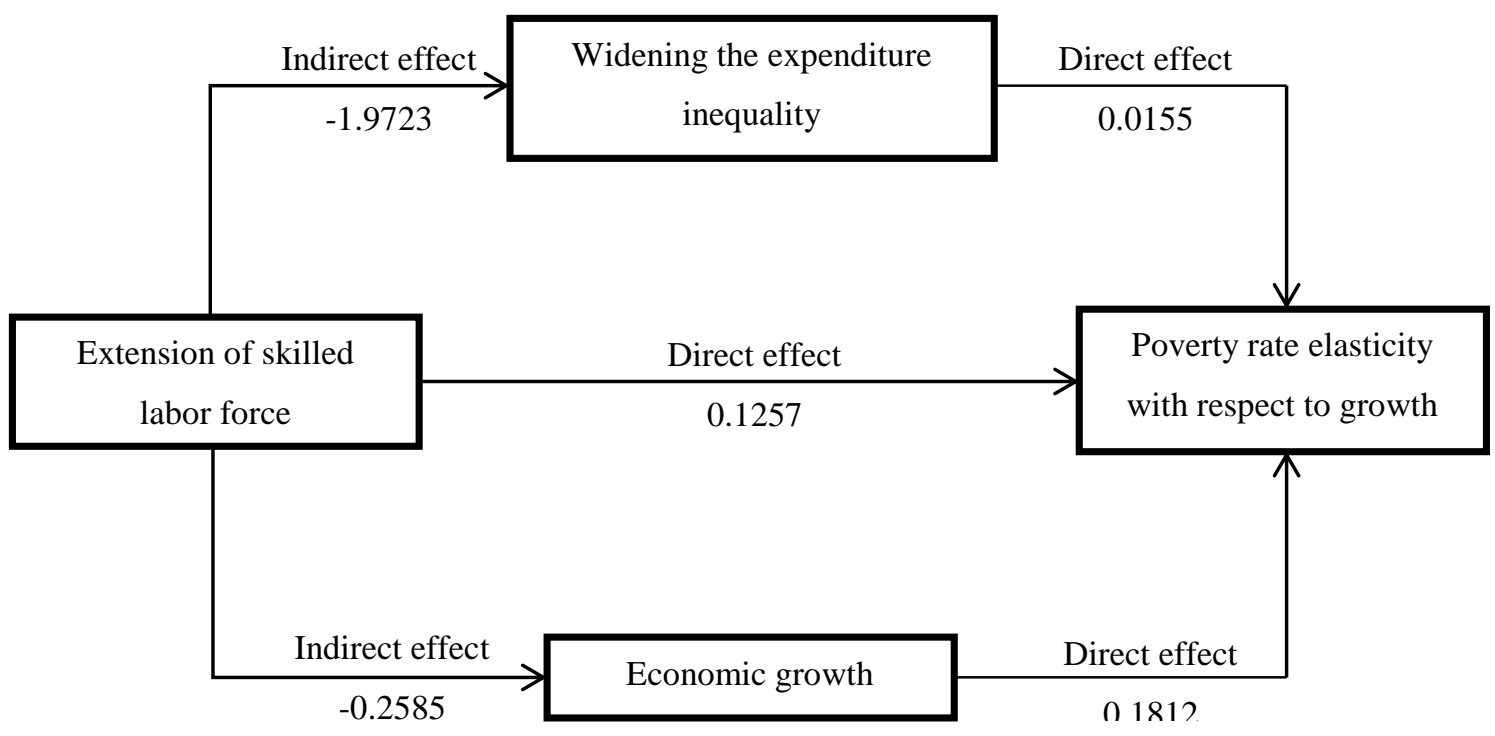

(v) HCMC and Dong Nai, Quang Ninh, Quang Tri, Dak Nong, Binh Thuan, and Ha Giang provinces are the exceptional cases when they have positive growth elasticity of poverty rate (Fig. 3 and the results from the Equation 9). The economic growth rates for those do not contribute to the reduction of poverty rates;

(vi) The poverty rate elasticity with respect to growth positively affects economic growth (Equation 10); and the extension of agricultural sector does not contribute to the provincial economic growth because of the inefficiency in this sector; 
(vii) The province with more sources of income will have higher growth of Gini coefficient; and the extension of skilled labor force will help reduce expenditure inequality.

Elasticity of poverty gap with respect to growth

(viii) The similar findings are found in the system of Equations 12, 13, and 14. HCMC, Dong Nai, Quang Tri, and Khanh Hoa provinces are the exceptional cases because of their positive growth elasticity of poverty gap (Fig. 4 and the results from the Equation 12).

(ix) The striking finding is that Khanh Hoa Province has reduced the poverty rate but failed to prevent the poverty gap from increasing within two concerned years (comparing Fig. 2 and Fig. 3).

(x) Even though Quang Ninh, Dak Nong, Binh Thuan, and Ha Giang have reduced the poverty gap, their poverty rates increased (comparing Fig. 2 and Fig. 3).

Elasticity of squared poverty gap with respect to growth

(xi) Khanh Hoa and Quang Tri provinces are two exceptional cases when they have not only positive squared poverty gap with respect to growth (Fig. 4), but also positive squared poverty gap with respect to Gini coefficient (Fig. 7). The economic growth and expenditure inequality generate the severe gap within the poor.

\section{Conclusions}

The fundamental methodologies employed in this paper are the comparative and descriptive data analysis and the simultaneous equation system. The elasticity of poverty with respect to growth and elasticity of poverty with respect to Gini coefficient are used to measure efforts to reduce poverty with respect to growth and to measure the impacts of expenditure inequality on poverty along the line suggested by McKay (2007). The simultaneous equation system is used to analyze not only direct and indirect effects of the related variables, but also the causality effect between economic growth and the poverty elasticity with respect to growth. The researched data sets were obtained from the Vietnam's Government Statistical Office and the Vietnamese Household Living Standard Surveys (VHLSS2010 and VHLSS2008) in the years of 2008 and 2010.

The main findings and the policy implications of the research are as follows: 
(i) Impacts of provincial economic growth on poverty reduction comparatively vary across the nation. Based on the national average growth rate and the national poverty elasticity with respect to growth, four groups are comparatively defined: (1) achieving high economic growth and poverty reduction; (2) achieving high economic growth but no poverty reduction; (3) achieving poverty reduction but no economic growth; and (4) achieving neither economic growth nor poverty reduction. The Vietnamese government needs to identify where economic growth translates into poverty reduction, and where it does not.

(ii) Impacts of the widening inequality on poverty reduction also vary across the nation. Based on the national average Gini growth rate and the national poverty elasticity with respect to Gini, four groups are comparatively defined: (1) achieving low Gini growth rate and poverty reduction; (2) achieving low Gini growth rate but no poverty reduction; (3) achieving poverty reduction but no low Gini growth rate; and (4) achieving neither low Gini growth rate nor poverty reduction.

(iii) The poverty elasticity with respect to growth is a behavioral function of: (1) Gini coefficient at the base year; (2) the growth of the Gini coefficient; (3) economic growth; and (4) the extension of skilled labor force. It implies that the initial expenditure inequality, growth of expenditure inequality within two related years (2008 and 2010), the provincial economic growth, and the extension of skilled labor significantly impact on the poverty elasticity with respect to growth. Thus, local authorities should enhance the vocational training programs and generate the efficient works.

(iv) The extension of provincial skilled labor directly impacts on the poverty elasticity with respect to growth and indirectly impacts on poverty elasticity with respect to growth through the expenditure inequality and economic growth. The Vietnamese government and local authorities might intuitively recognize the multidimensional aspects of the skilled labor force.

(v) Two striking findings are: (1) Khanh Hoa Province has successfully reduced the poverty rate but failed to prevent the poverty gap from increasing within two concerned years; and (2) Quang Ninh, Dak Nong, Binh Thuan, and Ha Giang provinces have successfully reduced the poverty gap while their poverty rates became higher. The poverty alleviation policies of Khanh Hoa Province are different from those adopted by the other four provinces 


\section{Note}

[1] The depth of poverty is sometimes summarized as the average shortfall of the poor below the poverty line, which is also equal to the ratio $\mathrm{P} 1 / \mathrm{P} 0$.

\section{References}

Datt, G., \& Ravallion, M. (1992). Growth and redistribution components of changes in poverty: A decomposition with application to Brazil and India. Journal of Development Economics, 38(2), 275-295.

Grimm, M., Klasen, S., \& McKay, A. (2007). Determinants of pro-poor growth: Analytical issues and findings from country cases. UK: Palgrave Macmillan.

Institute of Social Sciences. (2011). Poverty reduction in Vietnam: Achievements and challenges (in Vietnamese). Hà Nội, Vietnam: The Gioi Publisher.

Kakwani, N., \& Pernia, E. M. (2000). What is pro-poor growth? Asian Development Review, 18(1), $1-16$.

Kakwani, N., Khandker, S., \& Son, H. H. (2004). Pro-poor growth: Concepts and measurements with country case studies (Working Paper No. 1). Brazil: International Poverty Centre (IPC).

Lopez, J. H. (2004). Pro-poor growth: A review of what we know (and what we don't). Washington DC: World Bank's PREM Poverty Group.

McKay, A. (2002). Defining and measuring inequality (DFID-ERC Briefing Paper on Inequality No. 1). Retrieved Dec. 29, 2013 from http://www.odi.org.uk/PPPG/publications/briefings/ inequality_briefing/01.pdf

Ravallion, M. (2004). Pro-poor growth: A primer, development research group. Washington DC: World Bank.

Ravallion, M., \& Chen, S. (2003). Measuring pre-poor growth. Economics Letters, 78(1), 93-99.

Sen, B., Mujeri , M. K., \& Shahabuddin, Q. (2004). Operationalizing pro-poor growth: Bangladesh as a case study. Paper commissioned by AfD, BMZ (GTZ and KfW), DFID and the World Bank.

Timmer, C. P. (2005). Operationalizing pro-poor growth: Indonesia. Paper commissioned by AfD, BMZ (GTZ and KfW), DFID and the World Bank.

World Bank. (2012). Well begun, not yet done: Vietnam's remarkable progress on poverty reduction and the emerging challenges (Report No. 70798-VN), Hà Nội. 